\title{
PENERAPAN STANDAR OPERASIONAL PROSEDUR PADA KLINIK UTAMA VINCENTIUS KRISTUS RAJA SURABAYA
}

\author{
Jeanne Asteria Wawolangi ${ }^{1}$, Anita Permatasari ${ }^{2 *}$ \\ ${ }^{1,2}$ Program Studi Akuntansi, Fakultas Ekonomi, Universitas Katolik Darma Cendika \\ Jalan Dr. Ir. H. Soekarno 201, Surabaya \\ *Corresponding Author: anita.permatasari@ukdc.ac.id
}

\begin{abstract}
Vincentius Kristus Raja (KR) Main Clinic aims to serve patients effectively and economically in an effort to improve the quality of public health services, especially in Surabaya. This type of research is descriptive qualitative in the form of a case study, to assess the implementation of standard operating procedures at the Vincentius Kristus Raja Main Clinic. Relevant data collection was carried out using questionnaires distributed to personnel related to standard operating procedures. The results of the research study according to the questionnaire indicate that the operational implementation is in accordance with the standard operating procedures that have been set based on the policies of the leadership and the Vincentius Kristus Raja Main Clinic Foundation. Compliance with standard operating procedures is very important because standard operating procedures are guidelines or references for carrying out tasks and work in accordance with their functions. The conclusions and suggestions from this study are that although compliance with standard operating procedures is adequate, the Vincentius Kristus Raja Main Clinic needs to develop and improve the quality of services, especially better communication with patients, both new patients and patients who have been on treatment for a long time at the Vincentius Kristus Raja Main Clinic. Considering that there are now many new health clinics that can be competitors for the Vincentius Kristus Raja Main Clinic, there must be a good response to this phenomenon. The emergence of these new competitors requires the Vincentius Kristus Raja Main Clinic to be able to be competitive in order to face the existing competition by improving the quality and quality of service for patients.
\end{abstract}

Keywords: standard operating procedures, Vincentius Kristus Raja Main Clinic, application of standard operating procedures.

\footnotetext{
ABSTRAK

Klinik Utama Vincentius Kristus Raja (KR) bertujuan untuk melayani pasien secara efektif dan ekonomis dalam upaya meningkatkan mutu pelayanan kesehatan masyarakat, khususnya di Surabaya. Jenis penelitian ini adalah kualitatif deskriptif dengan bentuk studi kasus, untuk menilai penerapan terhadap pelaksanaan standar operasional prosedur operasional di Klinik Utama Vincentius
} 
Kristus Raja. Pengumpulan data yang relevan dilakukan dengan menggunakan media kuesioner yang dibagikan kepada personil-personil yang berkaitan dengan standar operasional prosedur. Hasil kajian penelitian menurut kuesioner menunjukkan bahwa penerapan operasional telah sesuai dengan standar operasional prosedur yang telah ditetapkan berdasarkan kebijakan pimpinan dan Yayasan Klinik Utama Vincentius Kristus Raja. Kepatuhan terhadap standar operasional prosedur ini sangat penting karena standar operasional prosedur merupakan pedoman atau acuan untuk melaksanakan tugas dan pekerjaan sesuai dengan fungsinya. Simpulan dan saran dari penelitian ini adalah meskipun kepatuhan terhadap standar operasional prosedur operasional sudah memadai tapi Klinik Utama Vincentius Kristus Raja perlu adanya pengembangan dan peningkatan kualitas pelayanan, khususnya komunikasi yang lebih baik dengan para pasien, baik pasien yang baru maupun pasien yang sudah lama berobat di Klinik Utama Vincentius Kristus Raja. Mengingat saat sekarang banyak bermunculan klinik-klinik kesehatan baru yang dapat menjadi pesaing bagi Klinik Utama Vincentius Kristus Raja, maka harus ada respons yang baik menghadapi fenomena ini. Timbulnya pesaing-pesaing yang baru ini mengharuskan Klinik Utama Vincentius Kristus Raja untuk mampu menjadi kompetitif guna menghadapi persaingan yang ada dengan cara meningkatkan kualitas dan mutu pelayanan bagi para pasien.

Kata kunci: standar operasional prosedur, Klinik Utama Vincentius Kristus Raja, penerapan standar operasional prosedur

\section{PENDAHULUAN}

Pelayanan publik Klinik Utama Vincentius Kristus Raja merupakan perwujudan pelayanan sosial bidang kesehatan bagi masyarakat Indonesia yang membutuhkan pemeliharaan kesehatan yang memadai, khususnya masyarakat di Surabaya dan sekitarnya. Penyediaan fasilitas layanan kesehatan yang baik diharapkan akan mampu memberikan pasien pelayanan kesehatan yang prima, sebab kesehatan merupakan faktor yang sangat penting bagi masyarakat. Pelayanan kesehatan yang baik dan memadai perlu adanya suatu standar operasional prosedur yang memadai, di mana standar operasional prosedur yang telah dibuat tersebut harus diimplementasikan oleh jajaran pimpinan dan Yayasan Klinik Utama Vincentius Kristus Raja.

Penerapan standar operasional prosedur dalam setiap tindakan operasional merupakan salah satu upaya untuk menjaga keselamatan pasien, meningkatkan pelayanan, dan menghindari tuntutan mal praktik (Taufiq, 2019). Pelayanan kesehatan yang memadai dapat menjadi indikator utama di dalam menilai Klinik Utama Vincentius Kristus Raja sudah baik atau belum kualitas pelayanannya yang dinilai mulai dari datangnya para pasien dan menunggu di ruang tunggu, kemudian para pasien tersebut akan dilayani sesuai urutan mendaftar dan menginformasikan keluhan sakit, kemudian oleh petugas klinik utama diarahkan ke dokter, dokter gigi, ataupun akupuntur. Semua tugas operasional yang 
diselesaikan harus sesuai dengan standar operasional prosedur, yang merupakan serangkaian instruksi tertulis yang dibakukan mengenai berbagai proses penyelenggaraan operasional di Klinik Utama Vincentius Kristus Raja dan semua petugas harus selalu mematuhi seluruh prosedur yang telah tertera di dalam standar operasional prosedur untuk memastikan semua kegiatan operasional berjalan dengan lancar (Sailendra, 2015: 11).

Adapun jenis standar operasional prosedur yang ada di Klinik Utama Vincentius Kristus Raja adalah standar operasional prosedur pendaftaran pasien, standar operasional prosedur pelayanan obat, standar operasional prosedur pelayanan klinik umum, standar operasional prosedur pelayanan klinik gigi, standar operasional prosedur tindakan gawat darurat klinik gigi, standar operasional prosedur pelayanan klinik akupuntur. Mutu pelayanan harus diupayakan secara terus menerus, dan sumber daya manusianya menjadi salah satu aset terpenting terutama perihal pengetahuan, sikap, dan keyakinan, serta sistem pemberian penghargaan dan sanksi. Hal tersebut harus menjadi perhatian yang serius dari pimpinan sehingga terjadi keharmonisan dalam berperilaku organisasi (Tjatur et al., 2018).

Pentingnya penerapan standar operasional prosedur dalam setiap tindakan operasional di klinik merupakan tanggung jawab semua petugas untuk mencapai pengendalian aktivitas yang tujuan akhirnya dapat mencapai good governance (Kaunang, 2012: 101). Kedisiplinan dalam mematuhi dan menerapkan standar operasional prosedur dapat memberikan standar pelayanan yang memadai bagi para pasien yang meliputi lama waktu tunggu pasien sebelum ditangani oleh para dokter, dokter gigi, dan akupuntur, kemudian waktu mulai dari diperiksa, ditangani secara medis sampai dengan proses pemberian resep obat jadi dan racikan yang sesuai dengan keluhan sakit para pasien. Kepatuhan terhadap penerapan standar operasional prosedur dapat mencapai manajemen mutu yang baik dan akan menjadi penggerak bagi aspek produktivitas dan efisiensi, serta meningkatkan hasil guna aset yang berdampak terhadap peningkatan kemampuan dan perluasan pasar serta perolehan keuntungan atau profit.

\section{TINJAUAN PUSTAKA}

\section{Pengertian Standar Operasional Prosedur}

Standar operasional prosedur adalah dokumen yang lebih jelas dan rinci untuk menjabarkan metode yang digunakan dalam mengimplementasikan dan melaksanakan kebijakan dan aktivitas organisasi sesuai pedoman yang merupakan instruksi tertulis untuk menyelesaikan suatu tugas rutin atau tugas yang berulang (repetitif) dengan cara yang efektif dan efisien untuk menghindari terjadinya penyimpangan yang dapat mempengaruhi kinerja organisasi secara keseluruhan (Soemohadiwidjaja, 2015: 91). Standar operasional prosedur menurut Umam et al. (2019) merupakan panduan yang digunakan untuk memastikan kegiatan operasional perusahaan agar berjalan dengan lancar. Hal-hal yang diperlukan dalam membuat standar operasional prosedur menurut Purnamasari (2015: 13) adalah: 
1. Konsistensi

Standar operasional prosedur sebagai suatu ketetapan atau prosedur kerja maka harus konsisten dan disiplin yang tinggi.

2. Efisiensi

Semua aktivitas kerja dilaksanakan secara cepat, cermat, dan tepat sesuai dengan tujuan atau hasil yang ingin diraih.

3. Meminimalkan kesalahan

Standar operasional prosedur menjadi panduan pasti atau prosedur kerja yang membimbing para karyawan bekerja secara sistematis dan jelas sehingga dapat meminimalkan kesalahan.

4. Penyelesaian masalah jika terjadi konflik sesama karyawan

Penyelesaian konflik tersebut akan dikembalikan di standar operasional prosedur yang ada. Semua pihak harus tunduk terhada standar operasional prosedur tersebut sehingga konflik dapat segera diatasi.

5. Perlindungan tenaga kerja

Standar operasional prosedur dimaksudkan untuk melindungi para karyawan yang berkaitan dengan persoalan karyawan, seperti sikap loyalitas karyawan terhadap perusahaan dan karyawan sebagai individu secara personal.

6. Peta kerja

Standar operasional prosedur menjadikan pola kerja lebih fokus dan tidak melebar kemana-mana. Hal ini sangat membantu kemajuan perusahaan juga mendukung aktivitas lebih disiplin.

7. Batasan pertahanan

Standar operasional prosedur secara prosedural semua aktivitas institusi ataupun perusahaan sudah tertera dengan sangat jelas.

\section{Tujuan dan Fungsi Standar Operasional Prosedur}

Adapun tujuan dan fungsi standar operasional prosedur menurut Purnamasari (2015: 16) adalah sebagai berikut:

1. Memberikan sebuah rekaman kegiatan dan pengoperasiannya secara praktis.

2. Mengetahui dengan jelas peran dan fungsi tiap-tiap posisi dalam organisasi.

3. Membentuk kedisiplinan kepada semua anggota organisasi baik dalam institusi, organisasi, maupun perusahaan.

4. Menjaga tingkat kinerja yang konsisten pada masing-masing unit kerjanya.

5. Memperlancar pekerjaan atau tugas bagi karyawan.

6. Ketika ada penyalah gunaan wewenang, standar operasional prosedur bisa dijadikan sebagai dasar hukum yang kuat untuk mengambil tindakan.

7. Memberikan kemudahan dalam menyaring, menganalisis, dan membuang hal-hal atau pekerjaan yang tidak sesuai dengan prosedur.

8. Untuk meminimalkan kesalahan atau kegagalan, keraguan, duplikasi, dan inefisiensi.

9. Memperbaiki kualitas atau performa karyawan.

10. Membantu menguatkan regulasi perusahaan.

11. Memastikan efisiensi tiap-tiap aktivitas operasional.

12. Menjalankan segala peralatan untuk keefektifan program pelatihan.

13. Memberikan kemudahan dalam melaksanakan pekerjaan sehingga semua 
karyawan menyadari akan tanggung jawab pekerjaan, memahami, dan mengetahui hak dan kewajibannya.

14. Melindungi organisasi atau unit kerja dan karyawan dari mal praktik atau kesalahan.

\section{Prinsip Penyusunan Standar Operasional Prosedur}

Prinsip-prinsip dalam penyusunan standar operasional prosedur menurut Sanoto (2020) adalah sebagai berikut:

1. Mudah dan jelas.

2. Dapat diukur.

3. Efisiensi dan efektivitas.

4. Dapat menyesuaikan kebutuhan.

5. Dapat menggambarkan alur kegiatan.

6. Keselarasan.

7. Memiliki orientasi pada pihak yang dilayani.

8. Ada kepatuhan hukum.

9. Adanya kepastian hukum.

10. Transparansi dan keterbukaan.

\section{Prinsip Pelaksanaan Standar Operasional Prosedur}

Prinsip pelaksanaan standar operasional prosedur menurut Kementerian Pendayagunaan Aparatur Negara dan Reformasi Birokrasi (2012) yang dituangkan dalam Peraturan Menteri Pendayagunaan Aparatur Negara dan Reformasi Birokrasi Nomor PER/35/M.PAN/06/2012 tentang Pedoman Penyusunan Standar Operasional Prosedur (SOP) Administrasi Pemerintahan sebagai pengganti Peraturan Menteri Pendayagunaan Aparatur Negara dan Reformasi Birokrasi Nomor Nomor PER/21/M.PAN/11/2008 adalah sebagai berikut:

1. Konsisten

Standar operasional prosedur yang telah disusun harus dilaksanakan secara konsisten oleh semua jajaran di perusahaan, dari waktu ke waktu oleh siapapun, dan dalam kondisi apapun.

2. Komitmen

Standar operasional prosedur harus dilaksanakan dengan komitmen yang tinggi dari seluruh jajaran organisasi, mulai dari level rendah sampai level yang tertinggi.

3. Perbaikan berkelanjutan

Pelaksanaan standar operasional prosedur harus terbuka terhadap penyempurnaan untuk memperoleh prosedur yang lebih efektif dan efisien.

4. Mengikat

Standar operasional prosedur harus mengikat yang melaksanakan tugas dan sesuai dengan prosedur atau pedoman yang sudah ditetapkan.

5. Seluruh unsur memiliki peran penting

Seluruh karyawan memiliki peran-peran tertentu dalam setiap prosedur yang distandarkan. Seorang karyawan tidak melakukan perannya dengan baik, maka akan mengganggu keseluruhan proses, sehingga berakibat pada proses 
penyelenggaraan perusahaan. Contohnya, karyawan A kurang disiplin dalam mengerjakan tugas, tidak sesuai dengan prosedur yang berlaku, maka sikap ini akan berdampak pada hasil akhir yang kurang memuaskan.

6. Terdokumentasi dengan baik

Seluruh prosedur yang telah distandarkan harus dapat didokumentasikan dengan baik sehingga dapat dijadikan referensi bagi mereka yang memerlukan.

\section{Monitoring dan Evaluasi Penerapan Standar Operasional Prosedur}

Monitoring merupakan tahap yang paling penting dalam pelaksanaan standar operasional prosedur. Tahap ini dapat dijadikan tolok ukur penerapan standar operasional prosedur (Fatimah, 2015: 169). Tahapan yang dapat dilakukan dalam kegiatan monitoring standar operasional prosedur, yaitu:

1. Merencanakan kegiatan monitoring secara berkala.

2. Mempersiapkan tim monitoring.

3. Melaksanakan monitoring.

4. Membuat laporan terkait kegiatan monitoring yang dilakukan.

5. Membuat kesimpulan sementara sebagai bahan evaluasi.

6. Membuat usulan atau draft perbaikan standar operasional prosedur jika sekiranya diperlukan.

\section{Aplikasi Standar Operasional Prosedur}

Aplikasi standar operasional prosedur menurut Ekotama (2015: 97) dapat dilakukan melalui 6 cara berikut ini:

1. Training dasar.

2. Training tingkat lanjut.

3. Briefing berkala.

4. Evaluasi berkala.

5. Reward bagi pelaksana standar operasional prosedur.

Penyusunan standar operasional prosedur disusun oleh pimpinan atau atasan dari suatu organisasi, akan tetapi pada kenyataannya pimpinan organisai memberikan tugas kepada tim yang ditunjuk berdasarkan surat keputusan. Tim penyusunan standar operasional prosedur merupakan perwakilan dari setiap unit yang ada dalam organisasi tersebut. Tim yang ditunjuk dalam penyususnan standar operasional prosedur harus memiliki kemampuan atau kompetensi yang sesuai dengan bidang organisasi tersebut. Manajemen puncak juga harus memastikan bahwa perencanaan sistem manajemen mutu dan apabila terjadi perubahan sistem manajemen mutu, maka integritas tetap harus terjaga (Suwandi. 2012: 40).

Selain itu, perlu dilakukan aktivitas pengendalian dan program audit. Aktivitas pengendalian bertujuan untuk membantu memastikan bahwa tindakan yang diperlukan untuk menanggulangi risiko dalam pencapaian tujuan suatu perusahaan, sudah terlaksana ataukah belum (Agoes, 2012: 45). Program audit dengan tujuan dapat memberikan kontribusi terhadap efektivitas manajemen lingkungan dari perusahaan secara keseluruhan (Tunggal, 2000: 31). 


\section{METODE PENELITIAN}

Pendekatan penelitian ini menggunakan metode kualitatif deskriptif bentuk studi kasus. Tujuan penelitian ini adalah untuk memperoleh informasi yang berkaitan dengan penerapan standar operasional prosedur. Peneliti melakukan tindakan pengamatan dalam kondisi nyata di lapangan dengan telaah dokumen dan wawancara dengan personil yang terkait untuk memperoleh informasi jawaban yang tepat dan akurat. Teknik analisis yang digunakan dalam penelitian ini adalah menggunakan teknik analisis deskriptif yaitu mengkaji dan mendeskripsikan data dan menganalisis data yang terkumpul. Metode pengumpulan data berupa kuesioner dan wawancara.

\section{HASIL PENELITIAN DAN PEMBAHASAN}

Data dan informasi yang diperoleh peneliti menunjukkan bahwa kepatuhan terhadap penerapan standar operasional prosedur telah dilaksanakan dengan baik oleh Klinik Utama Vincentius Kristus Raja. Hal ini dapat dilihat, mulai dari pasien datang harus antri terlebih dahulu, kemudian menuju ke bagian pendaftaran (bagian front liner), lalu bagian pendaftaran melakukan registrasi, dan dicatat dalam buku administrasi sebagai pasien baru ataukah pasien lama. Pada bagian ini ada biaya pendaftaran kartu status atau catatan medik khususnya untuk pasien baru, setelah itu pasien diantar ke bagian pemeriksaan awal yaitu pemeriksaan tensi dan keluhan-keluhan khusus untuk dirujuk ke dokter atau akupuntur. Langkah selanjutnya, setelah diperiksa oleh dokter atau akupuntur maka diberi resep dan pasien tersebut menuju ke ruang pharmacy atau kamar obat, baik obat paten maupun obat racikan. Waktu tunggu pasien pada saat pengambilan obat tidak lama (sesuai standar operasional prosedur waktu tunggu pasien untuk mendapatkan obat) sesudah itu pasien membayar jasa dokter dan akupuntur dan diterima oleh bagian pendaftaran atau front liner saat melakukan tindakan ke pasien oleh dokter, dokter gigi, atau akupuntur maka harus mencatat di buku tindakan medis misalnya: dokter gigi, tembel gigi, bersihkan karang gigi, dengan demikian memudahkan jika akan dilakukan crosscek.

Pasien yang akan berobat gigi kepada dokter gigi dan ada tindakan-tindakan medis lainnya yang dilakukan oleh dokter gigi misalnya tembel gigi, bersihkan karang gigi, perawatan gigi, atau tindakan medis lainnya, maka pembayaran dilakukan ke dokter gigi dan pada akhir jam operasional selesai, maka akan ada petugas bendahara akan mengambil uang pembayaran dari pasien di front liner dan di dokter gigi juga di bagian pharmacy atau kamar obat karena adanya penjualan obat. Pada saat itu, semua jumlah uang yang diterima akan dihitung dan dicocokkan oleh petugas bendahara masing-masing dengan catatan sesuai dengan tindakan fasilitas kesehatan yang diterima oleh pasien dan juga catatan hasil penjualan obat. Alur operasional di Klinik Utama Vincentius Kristus Raja terlihat pada bagan di Gambar 1. Pelaksanaan Standar Operasi Prosedur di Klinik Utama Vincentius Kristus Raja sudah berjalan dengan baik akan tetapi perlu diadakannya evaluasi atas standar operasional prosedur dan dilakukannya monitoring periodik secara tertulis bukan hanya secara lisan saja. 


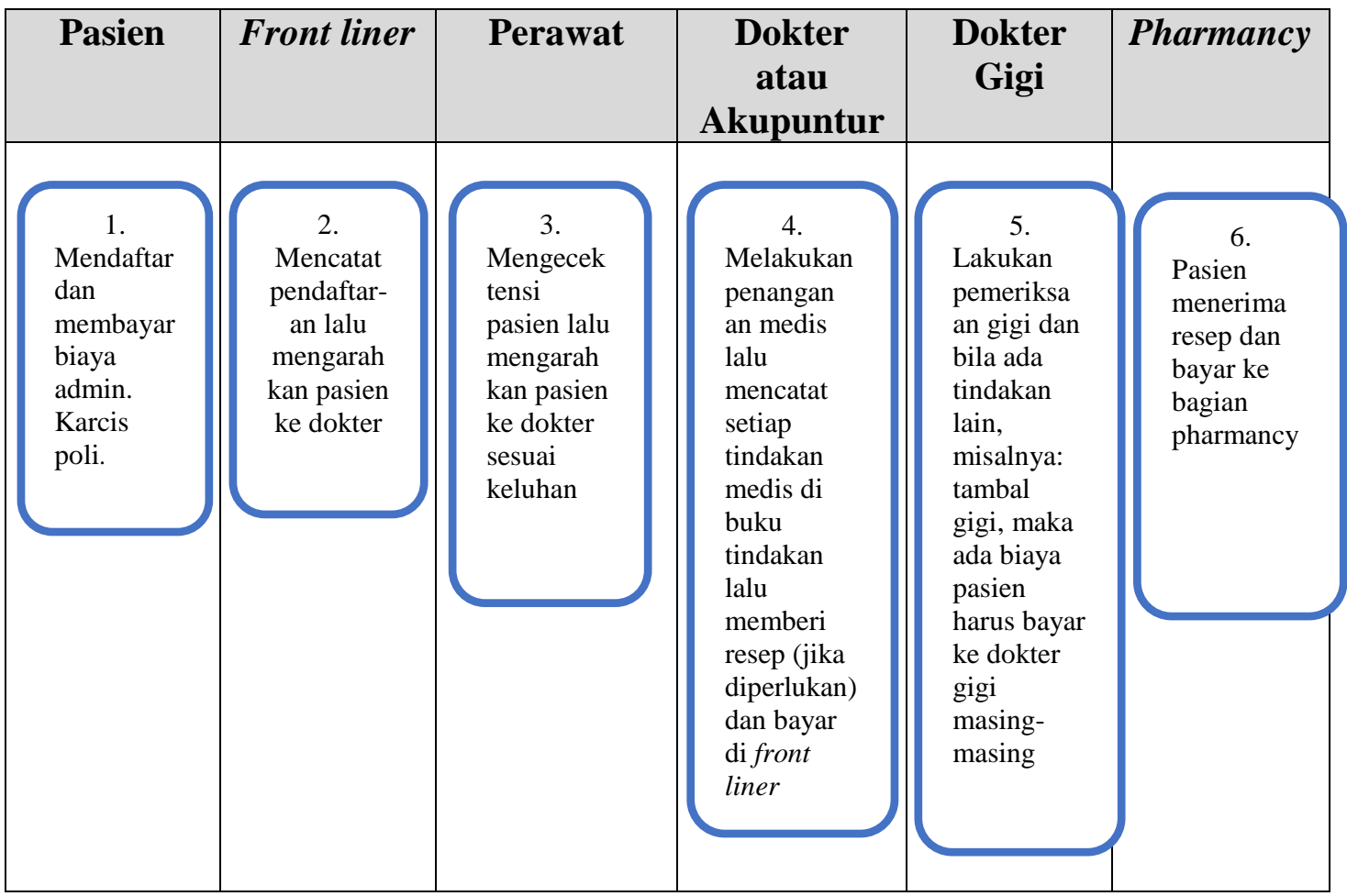

Sumber: Data Internal Klinik Utama Vincentius Kristus Raja dan Diolah oleh Peneliti

\section{Gambar 1 \\ Alur Operasional Klinik Utama Vincentius Kristus Raja}

Perangkapan tugas antara bagian kasir dengan pendaftaran tidak memenuhi standar pengendalian internal yang baik. Pengendalian internal yang baik mengharuskan bagian pendaftaran dan bagian kasir terpisah, sehingga harus ada bagian kasir tersendiri untuk menerima pembayaran dan bagian pendaftaran tersendiri untuk menangani perihal pendaftaran pasien. Perlu adanya pembagian tugas yang berdasarkan prinsip-prinsip yaitu pemisahan fungsi pelaksana atau pendaftaran front liner antara fungsi penyimpanan aktiva atau kas.

\section{SIMPULAN}

Klinik Utama Vincentius Kristus Raja sudah mematuhi standar operasional prosedur yang telah ditetapkan oleh Yayasan. Standar operasional prosedur pada Klinik Utama Vincentius Kristus Raja sudah berjalan dengan lancar, hanya saja belum ada monitoring terhadap proses operasional. Bagian pendaftaran sebagai front liner selain mengurus pendaftaran para pasien juga menerima pembayaran dari pasien sesuai dengan biaya fasilitas kesehatan yang diterima oleh pasien dari dokter umum dan akupuntur.

Pembayaran oleh pasien ke dokter gigi sehubungan dengan fasilitas pelayanan gigi dan tindakan, misalnya tembel gigi dan membersihkan karang gigi. Belum ada evaluasi secara periodik dan secara tertulis terhadap hasil penerapan standar operasional prosedur pada Klinik Utama Vincentius Kristus Raja. Adanya 
pelaporan keuangan secara sederhana yang dibuat oleh bagian admin dan diserahkan ke yayasan sebagai laporan pertanggung jawaban. Pembuatan standar operasional prosedur tertanggal 1 Oktober 2010.

\section{SARAN}

Mengingat pentinganya standar operasional prosedur, maka kepatuhan dan penerapan standar operasional prosedur hendaknya tetap dipertahankan di Klinik Utama Vincentius Kristus Raja. Standar operasional prosedur telah berjalan dengan lancar tapi tetap harus ada evaluasi tertulis tentang realisasi dibandingkan dengan standar operasional prosedur yang berlaku di Klinik Utama Vincentius Kristus Raja dan dianalisa oleh Yayasan. Perlu ada pemisahan fungsi antara bagian pendaftaran dengan yang menerima uang. Perlu adanya kasir yang fungsinya menerima dan mengeluarkan uang yang terpisah dari bagian pendaftaran untuk menjaga penerapan pengendalian internal yang baik.

Langkah selanjutnya untuk mengantisipasi perkembangan pelayanan kesehatan, maka Klinik Utama Vincentius Kristus Raja perlu berbenah agar pelayanan kesehatan lebih memadai dan dapat meningkatkan pendapatan klinik. Perlu adanya kerjasama dengan unit-unit yang ada di paroki ataupun unit-unit lainnya agar dapat meningkatkan jumlah pasien, sehingga diharapkan akan ada peningkatan pendapatan dan kesejahteraan para dokter, akupuntur, dan dokter gigi yang bekerja di Klinik Utama Vincentius Kristus Raja. Perlu adanya analisis dan penilaian terhadap peningkatan pendapatan dalam laporan keuangan. Pembuatan standar operasional prosedur pada tahun 2010 perlu dievaluasi, direvisi, dan diperbaharui agar standar operasional prosedur tersebut dapat mengikuti perkembangan klinik pada tahun-tahun terakhir.

\section{DAFTAR PUSTAKA}

Agoes, S. 2012. Auditing Petunjuk Praktis Pemeriksaan Akuntan oleh Kantor Akuntan Publik. Edisi 4. Buku 1. Salemba Empat. Jakarta.

Ekotama, Suryono. 2015. Pedoman Mudah Menyusun SOP. Media Pressindo. Yogyakarta.

Fatimah, Endah Nur. 2015. Strategi Pintar Menyusun SOP. Pustaka Baru Press. Yogyakarta.

Kaunang, Alfred F. 2012. Pedoman Audit Internal. Bhuana Ilmu Populer. Gramedia. Jakarta.

Kementerian Pendayagunaan Aparatur Negara dan Reformasi Birokrasi. 2012. Peraturan Menteri Pendayagunaan Aparatur Negara dan Reformasi Birokrasi Nomor PER/35/M.PAN/06/2012 tentang Pedoman Penyusunan Standar Operasional Prosedur (SOP) Administrasi Pemerintahan. Jakarta.

Purnamasari, Evita P. 2015. Panduan Menyusun SOP. Kobis. Yogyakarta.

Sailendra, Annie. 2015. Langkah-Langkah Praktis Membuat SOP. Cetakan Pertama.Trans Idea Publishing. Yogyakarta. 
Sanoto. 2020. Penyusunan Standard Operating Procedures (SOP) Pada Dinas Pendidikan Kabupaten Bengkayang Dalam Rangka Peningkatan Mutu Manajemen Organisasi. Jurnal Pendidikan dan Kebudayaan, Vol. 10, No. 3, pp. 263-268.

Soemohadiwidjaja, A.T 2015. Mudah Menyusun Standard Operating Procedure. Penebar Plus. Jakarta.

Suwandi, U. 2012. Pedoman Penerapan Sistem Manajemen Mutu ISO 9001:2000. Remaja Rosdakarya. Bandung.

Taufiq, A. R. 2019. Penerapan Standar Operasional Prosedur (SOP) dan Akuntanbilitas Kinerja Rumah Sakit. Jurnal Profita: Komunikasi Ilmiah Akuntansi dan Perpajakan, Vol. 12, No. 1, pp. 56-66.

Tjatur, Dicky Dewanto, Sonya Dewi Wulandari, Nurcahyo Andarusito, dan Gemala Hatta. 2018. Dampak Pencapaian Standar Pelayanan Minimal (SPM) Pada Unit Farmasi Rumah Sakit Umum Daerah, Lerik Kupang. Jurnal Manajemen dan Administrasi Rumah Sakit Indonesia (MARSI), Vol. 2, No. 2, pp. 36-51.

Tunggal, A.W. 2000. Audit Manajemen Kontemporer. Edisi Revisi. Harvarindo. Jakarta.

Umam, K., A. Idris, dan G. Riady. 2019. Analisis Penerapan Standar Operasional Prosedur dalam Meningkatkan Pelayanan Publik di Kelurahan BAQA Kecamatan Samarinda Sebrang Kota Samarinda. eJournal Pemerintahan Integratif, Vol. 7, No. 2, pp. 266-275. 